\title{
Review of Valentin Beck, Henning Hahn, and Robert Lepenies' (eds.) Dimensions of Poverty: Measurement, Epistemic Injustices, Activism. Cham: Springer, 2020, 412 pp.
}

\author{
S. SUBRAMANIAN \\ Independent Scholar
}

This book is the second volume in a series titled Philosophy and Poverty, the objective of which, we are told, is to provide "a forum for the whole range of philosophical research on poverty and poverty alleviation, broadly construed" (ii). As such, the project is a large one, in both scope and ambition. The essays in the present volume represent a selection from the proceedings of the Conference on Dimensions of Poverty held in Berlin in 2017, and are intended to cover the themes of "Measurement, Epistemic Injustices, Activism". Apart from an editorial introduction, the book features twenty contributions distributed across five thematic concerns: "Poverty as a Social Relation", "Epistemic Injustices in Poverty Research", "Philosophical Conceptions in Context", "Measuring Multidimensional Poverty", and "Country Cases". One must expect that the nature, quality, and range of the essays collected in the book must inevitably be dictated by the papers presented at, and available from, the conference from which they have originated, which presumably constitutes a model different from one in which a book's editors have the freedom of commissioning papers. The first model has limitations not shared by the second one, and I imagine this must be borne in mind when judging whether what I have referred to as the 'scope and ambition' of the project are quite realised in the volume under review.

The editorial introduction is a useful review of the themes sought to be addressed in the book, and of the specific chapters in it. Parts I and III ("Poverty as a Social Relation" and "Philosophical Conceptions in Context”, respectively) are perhaps best read together as reflecting a collection of concerns on some conceptual issues underlying the phenomenon of poverty. Part II, on "Epistemic Injustices in Poverty Research", consists of a set of four papers that must be welcomed-at least for their motivating intention-as suggesting engagement with concerns that are not part of the common currency of poverty studies. Parts IV and V, on multidimensional poverty measurement and country case studies, respectively, 
are relatively more 'mainstream' aspects of contemporary poverty analysis.

Parts I and III of the book, comprising six essays, are-as mentioned earlier-thematically connected by a concern, broadly, with philosophical approaches to answering the question 'what is poverty?' Among themselves, the relevant papers cover a set of well-worn issues, including absolute poverty, relative poverty, the capabilities approach to poverty assessment, poverty as a social relation, the place of social networks and social capital in understanding poverty, the enhanced effectiveness of aid when it is participatory and collaborative, and the importance of human rights as a normative guide to philanthropic impulse. Much of this work is unexceptionable, but not particularly novel, nor arresting. Indeed, one emerges from these reflections in a spirit of some jadedness, which is perhaps excusable in light of this sort of observation: "[...] human rights are morally important" (150). There is a suggestion in much of this of what one might call 'Poverty for Moral Dummies'. The complaint is not so much with the authors as with the apparent continuing need to address poverty in these terms for those that might still be interested in the subject, or worse, work on it. Of the more important conceptual issues undergirding the notion of poverty on which Amartya Sen has written are those pertaining to the 'capability perspective' and the distinction between absolute and relative poverty. On the capability approach, I am unable to see in this volume much advancement on, or useful alternative or complement to, what Sen has already said on the subject. On the distinction between absolute and relative poverty, some of the contributions have made me wonder if I have myself ever properly understood Sen on this important question. ${ }^{1}$

Certain issues in these philosophical reflections on poverty which I missed-and in no particular order of perceived importance-are the following.

(1) An assessment of the axiomatic bases of poverty measurement. In both unidimensional and multidimensional poverty measurement, there has been a long tradition of rationalizing poverty indices in terms of the axioms on which they have been built. As it happens, virtually every one of these axioms-focus, ${ }^{2}$ normalization, ${ }^{3}$ symmetry, ${ }^{4}$ continuity, ${ }^{5}$

\footnotetext{
${ }^{1}$ Sen (1979).

${ }^{2}$ Hassoun (2014).

${ }^{3}$ Basu (1985), Subramanian (2009b).

${ }^{4}$ On the 'anonymity' principle in 'liberal constitutions', see Loury (2000).

${ }^{5}$ Donaldson and Weymark (1986), Atkinson (1987).
} 
transfer, ${ }^{6}$ decomposability, ${ }^{7}$ scale invariance, ${ }^{8}$ and replication invariance $^{9}$ - has been subjected to scrutiny in the literature. An assessment of the ethical appeal and logical coherence of the axiomatic basis of aggregation in the poverty measurement literature would have been a welcome and integral component of any critical treatment of 'philosophy and poverty'.

(2) A more nuanced appreciation of the role of income in poverty assessment. As is well-known, and following principally on Sen's contributions to the conceptualization of poverty, there is now a substantial body of thought which prioritizes a 'capability' approach to poverty assessment over a 'resourcist' approach. It would be fair, I think, to suggest that the volume under review reflects this priority. This is not to say at all that the contributors to the volume have taken a uniformly dismissive view of the role of income (or more broadly, resources) in accounting for poverty, as evident, for example, in Jonathan Wolff: "As I have suggested, income adjustment, and, perhaps, the availability of new financial products is a very helpful way of addressing poverty" (37); or, again, Sanjay Reddy: "There is no necessary conflict between having a concern with the avoidance of income poverty and with recognizing that there are diverse nonincome concerns that must enter into poverty assessment, too" (217). Having said this, I believe it is possible that the volume might have achieved a greater and more subtle balance of perceptions if it had reflected the sort of critique of the 'capability perspective' that philosophers like Thomas Pogge ${ }^{10}$ have attempted in the past, wherein it is suggested that capability theorists have perhaps exaggerated the contrast between resources and capabilities in favour of the capability interpretation. Such an approach might also have facilitated an interesting consideration of the philosophical dimensions of a very simple measure of money-metric well-being that has been advanced by the economist Kaushik Basu (2001, 2006, 2013), which he calls 'the quintile income statistic' (the average income of the poorest 20 per cent of a population). The quintile income statistic offers the interesting possibility of viewing income not just as a means to an end (as in the usual 'identification-cum-aggregation' approach to poverty measurement), but as an end in itself, so that command over a reasonable level of income is seen as a valued human functioning

\footnotetext{
${ }^{6}$ Chateauneuf and Moyes (2005).

${ }^{7}$ Kanbur (2006).

${ }^{8}$ Kolm (1976a, 1976b), Krtscha (1994).

${ }^{9}$ Hassoun and Subramanian (2012).

${ }^{10}$ Pogge (2010a). See also Kelleher (2015).
} 
in and of itself. This is the sort of perspective that could lead logically to a consideration of 'basic income' as a policy instrument for the alleviation of poverty, and to political-economy considerations of feasibility, fiscal deficits, and the means of financing income support for the poor through, among other things, enhanced redistributive taxation. Philanthropy is discretionary, but taxation - of wealth and inheritance, for instance-is mandatory, and a more forceful means of seeking justice in the presence of undeserved want.

(3) Poverty and social groups. I am not suggesting an absence of this thematic concern in the volume, so much as underlining the desirability of an altogether more active and explicit presence of such concern in a disquisition on philosophy and poverty. What is the political economy of caste, race, and ethnicity in an understanding of poverty? ${ }^{11}$ How is group membership exploited and conflict fostered by the motive of establishing ownership over resources? ${ }^{12}$ How are marginalized groups (typically tribals and forest-dwellers) subjected to even greater oppression than would be warranted by the endemic prejudice that obtains against them, when local governments collaborate with multinational corporations in appropriating control over natural resources $?^{13}$ How might 'group-affiliation' externalities mediate the measurement of poverty? ${ }^{14}$ How might intergroup inequalities in the distribution of poverty call for targeting strategies that are different from what might be dictated solely by a concern with inter-personal inequalities? ${ }^{15}$ How might poverty-alleviation measures be influenced by an engagement with the ubiquitous but oftenmissed presence of 'horizontal inequality'? ${ }^{16}$ What values come into play in an assessment of poverty which is systematically informed by intergroup differentials in the societal distribution of burdens and advantages? ${ }^{17}$ These are some at least of the questions of philosophical interest that a concern with social groups should engender in analysing the phenomenon of poverty.

Part II of the volume deals with "epistemic injustices" in poverty research. Franziska Dübgen makes the point that epistemic and cognitive

\footnotetext{
${ }^{11}$ See, among others, Sundaram and Tendulkar (2003), Thorat and Newman (2010), Ashwini Deshpande (2011, 2013), Motiram and Singh (2012), and Satish Deshpande (2013).

${ }^{12}$ Mitra and Ray (2014).

${ }^{13}$ See, among others, Padel and Das (2010), Pogge (2010b), and Karat (2012).

${ }^{14}$ Subramanian (2009a).

${ }^{15}$ Keen (1992), Dasgupta and Kanbur (2005).

${ }^{16}$ Stewart (2005).

${ }^{17}$ See, for example, Dworkin (1977), and Galanter (2002).
} 
injustices are reflected in the marginalization of Southern researchers; in making 'others' the object rather than subject of research; in the neglect of subaltern knowledge and experience; and in the misconstruction of social reality. Jonathan Chimakonam specifically highlights the neglect of the Kenyan philosopher Odera Oruka and his theory of 'the human minimum' in the canvas of poverty studies. Sharon Adetutu Omotoso draws on the discourse on hair to draw a distinction between the 'Hairy' (associated with "Scholarly African Feminists" [SAF], 122) and the 'Hairless' (associated with "Indigenous-Survivalist African Feminists" [I-SAF], 122), and to focus attention on one aspect of deprivation that is frequently missed out in poverty studies, which she calls 'intellectual poverty'. Intellectual poverty is seen by the author to be a feature of both the 'Hairless' (the relatively less privileged materially deprived African women) and the 'Hairy' (the relatively more privileged, elitist class of African women, often with stable and well-paying jobs), but in different ways. For the 'Hairless', intellectual poverty is manifested as ignorance and lack of access to information which leads to irrationality, myopia, and reduced skills in problem-solving. For the 'Hairy', intellectual poverty is manifested in a lack of knowledge of, and attendant empathy for, the predicament of their 'Hairless' sisters. The resulting conflict between the SAF and I-SAF groups, stemming from intellectual poverty of one type or the other, is seen as being needless and unfortunate, and an impediment to combating the feminization of poverty. Finally, Mitu Sengupta considers the 'post-development' critique of poverty studies, in which much of poverty research from the Global North is perceived as being so shot through with epistemic injustice as to offer little hope for remediation in the form of less insular and more inclusive modes of understanding poverty. To address the question of whether academics (especially Western academics, as one understands) should engage in activism, the author reviews the post-development critique, in a somewhat autobiographical vein, by tracing her own association with poverty research under the aegis of the ASAP (Academics Stand Against Poverty) project. From what one can tell, the answer to the question resides in noting that there is good activism and bad activism, and activism which is humble and activism which isn't, so that if and where Western academic activism is of the good-and-humble type, "what's not to like" in it? - as the title of the article suggests.

As I have mentioned earlier, the issue of epistemic injustice in poverty research is not one that is commonly encountered in poverty studies. To the extent that this is true, it is certainly welcome that the problem has 
been flagged in this volume. Having said that, I believe it is not just interesting but also relevant to ask to what extent the phenomenon has actually been addressed in this collection-not least since it occupies an important place in its stated concerns (it is part of the book's title, and an entire section has been devoted to it). A quick count in the "About the Contributors" section (xi-xvi) yields thirty contributors in all, of whom twenty-five seem to be operating from the UK, the USA, Canada, Germany, France, Belgium, and Austria, while only four are from the global South: South Africa, Chile, Cameroon, and Nigeria, and one is from Taiwan. It is not just a matter of counting nationalities in the list of contributors. Rowntree and Booth are mentioned often in this volume in connection with identifying the absolute poor: unless I have missed something, I haven't seen a reference to the great Dadabhai Naoroji's ([1901] 1969) work in what amounted to deriving an 'absolute poverty line' for colonial India. (I know: Dadabhai who?) And it is not just the failure of the North to keep track of relatively rarefied and culture-specific work that occurs in the South. It is also failure of citation of significant peer research, following, for all one knows, from failure to even take note of research on areas that fall squarely within the ambit of the North's own research concerns. For instance, how much citation of work by Indian scholars working from India is there on unidimensional (money-metric) poverty and multidimensional poverty in India, as carried, for instance, in one of India's foremost social-science journals, the Economic and Political Weekly? ${ }^{18}$ It is good to be concerned with 'epistemic injustices' in poverty research. I state that without irony. I would merely add that it is also good to do something about it.

Part IV of the book on measuring multidimensional poverty has the largest number of contributions: seven. The first of these is by Sabina Alkire, another reminder "of the ongoing work on poverty research as it relates to multidimensional poverty measurement" (198). Sanjay Reddy, in his essay, offers an attractively brief critique of the protocols of

\footnotetext{
${ }^{18}$ Some of the earliest work on unidimensional poverty assessment by reference to a poverty line has been done in India. Prominent examples would include the poverty line advanced by the National Planning Committee under Jawaharlal Nehru in 1938; that advanced by the Indian Planning Commission (1962); a spate of papers-often in the form of debate-on the subject in the columns of the Economic and Political Weekly (EPW) in the early 1970s (special mention may be made of the work of Dandekar, Rath, Rudra, Minhas, and Bardhan); and several more perspectives on the issue, in the same journal, in the years to come (a small sample would include Sitaramam et al. 1996; Srinivasan 2007; Krishnaji 2012; and Subramanian 2014, 2015); and elsewhere (for example, Swaminathan 2010). The $E P W$ has also been a platform for work on multidimensional poverty (as in Jayaraj and Subramanian 2009, and Sengupta 2016).
} 
unidimensional (money-metric) measurement that preside over the approaches adopted by the World Bank and the governments of India and the USA. Much of this criticism is a continuation and summarisation of work he has himself done earlier, and it is a pity that his objections have still not been met in the vastly misleading work on money-metric poverty which continues to be done in the World Bank and official Indian and US traditions. (One is reminded here of the humourist Allan Laing's take on how Damon Runyon might have reacted to Henry James' prose: "[...] however long [he] snow[s], I am not getting [his] drift, so what is the use of going around with [him]?" ${ }^{19}$ ) Caroline Dotter and Stephan Klasen use Indian data to illustrate what happens when we change indicator thresholds for certain dimensions of multidimensional poverty to reflect the possibility that absolute requirements in the space of functionings may elicit varying (relative) requirements in the space of resources.

The next three essays in Part IV deal with how one may come up with a list of dimensions to be employed in multidimensional poverty measurement. Xavier Godinot and Robert Walker reflect on how such a list might emerge, not through the fiat of 'experts', but through a participative and collaborative procedure of consultation with those that actually experience poverty, by way of a strategy which they call the "Merging of Knowledge" (269). In a second contribution, by Francesco Burchi, Nicole Rippin, and Claudio Montenegro, dimensions are sought to be identified by attempting to trace an agreement on chosen dimensions by locating overlapping areas of congruence in countries' constitutional provisions, supplemented by what the authors refer to as "the public consensus approach" (286), participatory studies, and surveys. Nicolas Brando and Katarina Fragoso suggest that the dimensions of deprivation reckoned in extant measures are inadequate because of their overwhelming focus on material and biological deprivations, to the neglect of 'relational' deprivation, as manifested in the lack of control and autonomy needed to convert resources into functionings, even in the presence, formally, of access to these resources.

In a spirit akin to that in which I have made some observations earlier on the concern for epistemic injustice in poverty studies, I would like to draw attention to a refreshingly honest and straightforward comment made by Godinot and Walker on the quest for a generally acceptable list of dimensions for use in multidimensional poverty measurement:

${ }^{19}$ Laing $(1951,178)$. 
And, one might hope, if the policy community is open to novel dimensions suggested by the research, developing appropriate indicators will be undertaken in partnership with people having direct experience of poverty. The fact that it takes courage to write the preceding sentence which the reader might find ludicrously optimistic, underlines just how far the rhetoric of participation in international governance is distanced from practice. (271)

The above quote provokes speculation on yet another aspect of paternalism and the Hegemony of the Expert in poverty analysis. Multidimensional poverty measurement of a certain sort requires us to specify dimensions of deprivation, indicators within each dimension, and thresholds within each indicator-as well as various possible compromises between 'intersection' and 'union' approaches to the identification of the multidimensionally poor. Many of these choices have already been made in the publications of supra-national institutions. The requirement of 'comparability' across countries will surely gravitate in the direction of eliciting compliance from all countries on norms, procedures, and measures. This has already happened with unidimensional (money-metric) poverty, and it should be no surprise if a similar thing should also happen with multidimensional poverty (if it has not already happened). I speak of a situation in which 'If It Is Unidimensional Poverty, It Must Be The World Bank's Dollar-A-Day', and 'If It Is Multidimensional Poverty, It Must Be The UNDP's MPI', just as 'If It Is Tuesday, This Must Be Belgium'.

Returning to Part IV of the book, the seventh contribution deals with a particularly problematic dimension of deprivation, one-such as longevity or child mortality - which requires unavoidable engagement with the activity of valuing life. For those that value life infinitely, multidimensional poverty measures cannot entertain dimensions which entail a trade-off between the value of life and values in other dimensions. Is the project of multidimensional poverty measurement thereby unsalvageably jeopardised? Nicole Hassoun, Anders Herlitz, and Lucio Esposito address this interesting question, and suggest that multidimensional poverty measurement is still possible even when the comparability of the value of life with other values is denied, so long as incommensurability is combined with the notion that the value of life trumps all other values (though it may not be possible to say by 'how much').

The collection winds up, in Part V, with three useful country studies of multidimensional poverty in Cameroon, Germany, and Bangladesh. 
By way of summing up, I would say that the volume under review reflects a certain drying-up of fresh research perspectives on poverty, as well as a certain tiredness with its subject of enquiry. This is manifested in various instances of convolution, repetition, triteness, and fine-tuning. The book does not want for effort or good intent, but in terms of outcome it is, in the end, disappointing - with few but honourable exceptions (in which I would specifically include the contributions of Reddy; Godinot and Walker; Burchi, Rippin, and Montenegro; Hassoun, Herlitz, and Esposito; and Hans Mpenya, Francis Baye, and Boniface Epo).

\section{REFERENCES}

Atkinson, Anthony B. 1987. "On the Measurement of Poverty." Econometrica 55 (4): 749764.

Basu, Kaushik. 1985. "Poverty Measurement: A Decomposition of the Normalization Axiom." Econometrica 53 (6): 1439-1443.

Basu, Kaushik. 2001. "On the Goals of Development.” In Frontiers of Development Economics: The Future in Perspective, edited by Gerald M. Meier and Joseph E. Stiglitz, 61-86. New York, NY: Oxford University Press.

Basu, Kaushik. 2006. "Globalization, Poverty, and Inequality: What is the Relationship? What Can Be Done?" World Development 34 (8): 1361-1373.

Basu, Kaushik. 2013. "Shared Prosperity and the Mitigation of Poverty: In Practice and in Precept." Policy Research Working Paper No. 6700. The World Bank, Washington, DC.

Chateauneuf, Alain, and Patrick Moyes. 2005. "Measuring Inequality Without the PigouDalton Condition." Research Paper No. 2005/02. World Institute for Development Economics Research (UNU-WIDER), Helsinki.

Dasgupta, Indraneel, and Ravi Kanbur. 2005. "Community and Anti-Poverty Targeting." The Journal of Economic Inequality 3 (3): 281-302.

Deshpande, Ashwini. 2011. The Grammar of Caste: Economic Discrimination in Contemporary India. New Delhi: Oxford University Press.

Deshpande, Ashwini. 2013. Affirmative Action in India. New Delhi: Oxford University Press.

Deshpande, Satish. 2013. "Caste and Castelessness: Towards a Biography of the 'General Category'.” Economic and Political Weekly 48 (15): 32-39.

Donaldson, David, and John A. Weymark. 1986. "Properties of Fixed-Population Poverty Indices." International Economic Review 27 (3): 667-688.

Dworkin, Ronald. 1977. Taking Rights Seriously. Cambridge, MA: Harvard University Press.

Galanter, Marc. 2002. "Righting Old Wrongs." In Martha Minow's Breaking the Cycles of Hatred: Memory, Law, and Repair, edited by Nancy L. Rosenblum, 107-131. Princeton, NJ: Princeton University Press.

Hassoun, Nicole. 2014. "An Aspect of Variable Population Poverty Comparisons: Does Adding a Rich Person to a Population Reduce Poverty." Economics \& Philosophy 30 (2): 163-174.

Hassoun, Nicole, and S. Subramanian. 2012. "An Aspect of Variable Population Poverty Comparisons.” Journal of Development Economics 98 (2): 238-241. 
Jayaraj, D., and S. Subramanian. 2009. "A Chakravarty-D'Ambrosio View of Multidimensional Deprivation: Some Estimates for India.” Economic and Political Weekly 45 (6): 53-65.

Kanbur, Ravi. 2006. “The Policy Significance of Inequality Decompositions.” The Journal of Economic Inequality 4 (3): 367-374.

Karat, Brinda. 2012. "Of Mines, Minerals and Tribal Rights." The Hindu. Accessed May 15, 2012. https://www.thehindu.com/opinion/lead/of-mines-minerals-and-tribalrights/article3419034.ece.

Keen, Michael. 1992. "Needs and Targeting.” The Economic Journal 102 (410): 67-79.

Kelleher, J. Paul. 2015. “Capabilities versus Resources.” Journal of Moral Philosophy 12 (2): 151-171.

Kolm, Serge-Christophe. 1976a. "Unequal Inequalities. I.” Journal of Economic Theory 12 (3): 416-442.

Kolm, Serge-Christophe. 1976b. “Unequal Inequalities. II.” Journal of Economic Theory 13 (1): 82-111.

Krishnaji, Nidadavolu. 2012. “Abolish the Poverty Line.” Economic and Political Weekly 47 (15): 10-11.

Krtscha, Manfred. 1994. "A New Compromise Measure of Inequality." In Models and Measurement of Welfare and Inequality, edited by Wolfgang Eichhorn, 111-119. Heidelberg: Springer-Verlag.

Laing, Allan M. 1951. "Damon Runyon on Henry James." In The Phoenix Book of Wit and Humour, edited by Michael Barsley. London: Readers Union, Phoenix House.

Loury, Glenn C. 2000. "Racial Justice." Lecture given during the W. E. B. Du Bois Lectures at Harvard University, Cambridge, MA, April 17, 2000. http://www.bu.edu/irsd/ files/DuBois_3.pdf.

Mitra, Anirban, and Debraj Ray. 2014. "Implications of an Economic Theory of Conflict: Hindu-Muslim Violence in India.” Journal of Political Economy 122 (4): 719-765.

Naoroji, Dadabhai. (1901) 1969. Poverty and Un-British Rule in India. New Delhi: Publications Division, Ministry of Information and Broadcasting, Government of India.

Padel, Felix, and Samarendra Das. 2010. "Cultural Genocide and the Rhetoric of Sustainable Mining in East India." Contemporary South Asia 18 (3): 333-341.

Planning Commission. 1962. "Perspectives of Development, 1961-1976: Implications of Planning for a Minimum Level of Living." Reprinted in Poverty and Income Distribution in India, edited by Thirukodikaval N. Srinivasan, and Pranab K. Bardhan, 1974, 9-38. Calcutta: Statistical Publishing Society.

Pogge, Thomas. 2010a. “A Critique of the Capability Approach.” In Measuring Justice: Primary Goods and Capabilities, edited by Harry Brighouse, and Ingrid Robeyns, 1760. Cambridge: Cambridge University Press.

Pogge, Thomas. 2010b. Politics as Usual: What Lies Behind the Pro-Poor Rhetoric. Cambridge, MA: Polity Press.

Sen, Amartya. 1979. "Issues in the Measurement of Poverty." The Scandinavian Journal of Economics 81 (2): 285-307.

Sengupta, Anindita. 2016. "Gender Inequality in Well-being in India: Estimates from NFHS Household-level Data." Economic and Political Weekly 51 (13): 43-50.

Motiram, Sripad, and Ashish Singh. 2012. "How Close Does the Apple Fall to the Tree? Some Evidence from India on Intergenerational Occupational Mobility." Economic and Political Weekly 47 (40): 56-65. 
Sitaramam, Vetury, Sharayu A. Paranjpe, T. Krishna Kumar, Anil P. Gore, and J. G. Sastry. 1996. "Minimum Needs of Poor and Priorities Attached to Them." Economic and Political Weekly 31 (35/36/37): 2499-2505.

Srinivasan, Thirukodikaval N. 2007. "Poverty Lines in India: Reflections after the Patna Conference." Economic and Political Weekly 42 (41): 4155-4165.

Stewart, Frances. 2005. "Horizontal Inequalities: A Neglected Dimension of Development." In UNI-WIDER's Wider Perspectives on Global Development, 101-135. New York, NY: Palgrave Macmillan.

Subramanian, S. 2009a. "Poverty Measurement in the Presence of a 'Group-Affiliation' Externality." Journal of Human Development and Capabilities 10 (1): 63-76.

Subramanian, S. 2009b. "Revisiting the Normalization Axiom in Poverty Measurement." Finnish Economic Papers 22 (2): 89-98.

Subramanian, S. 2014. "The Poverty Line: Getting It Wrong Again... and Again.” Economic and Political Weekly 49 (47): 66-70.

Subramanian, S. 2015. “Once More Unto The Breach... The World Bank's Latest 'Assault' On Global Poverty." Economic and Political Weekly 50 (45): 35-40.

Sundaram, Krishnamurthy, and Suresh D. Tendulkar. 2003. "Poverty among Social and Economic Groups in India in 1990s.” Economic and Political Weekly 38 (50): 52635276.

Swaminathan, Madhura. 2010. "The New Poverty Line: A Methodology Deeply Flawed." Indian Journal of Human Development 4 (1): 121-125.

Thorat, Sukhadeo, and Katherine S. Newman, eds. 2010. Blocked by Caste: Economic Discrimination in Modern India. New Delhi: Oxford University Press.

S. Subramanian (b. 1953) studied at Loyola College (University of Madras), the Indian Institute of Management (Ahmedabad), and the London School of Economics and Political Science. He is a former Indian Council of Social Science Research (ICSSR) National Fellow, and a former professor of the Madras Institute of Development Studies. Subramanian is an elected fellow of the Human Development and Capability Association (HDCA). He has worked extensively on measurement and other aspects of poverty, inequality, and demography, and on topics in collective choice theory, welfare economics, and development economics. His published work has appeared in journals such as the Journal of Development Economics, The Journal of Development Studies, Social Choice and Welfare, Theory and Decision, and Mathematical Social Sciences. Some of his books are Rights, Deprivation, and Disparity: Essays in Concepts and Measurement (New Delhi: Oxford University Press, 2006), The Poverty Line (New Delhi: Oxford University Press, 2012), and Inequality and Poverty: A Short Critical Introduction (Singapore: Springer, 2019). In 2015, he was appointed as a member of the Advisory Board of the World Bank's Commission on Global Poverty under the Chairmanship of Sir Anthony Atkinson. He lives and works in Chennai.

Contact e-mail: <ssubramanianecon@gmail.com> 